\title{
Radiological study of cervical spine and hand in patients with rheumatoid arthritis of 15 years' duration: an assessment of the effects of corticosteroid treatment
}

\author{
J. J. RASKER* AND J.A. COSH
}

From the Royal National Hospital for Rheumatic Diseases, Bath

SUMMARY Radiological abnormalities in the cervical spine were assessed in detail in a group of 62 patients with rheumatoid arthritis of approximately 15 years' duration, of whom 33 had been treated with corticosteroids and 29 had not. The 10 criteria of damage described by Bland (1974), which include subluxation, correlated as a whole with the severity of the disease in general but not with the duration of corticosteroid treatment. Subluxation alone, whether assessed in the cervical spine as a whole or in the atlanto-axial joint alone, was less closely related to disease activity, was on average greater in patients treated with corticosteroids, and tended to increase in relation to the duration of treatment. Corticosteroid treatment thus tends to produce, over the course of years, a degree of subluxation in addition to that caused by the disease itself.

Radiological signs of damage to the metacarpophalangeal (MCP) joints and carpal bones correlated with both the degree of damage and the degree of subluxation in the cervical spine as well as with corticosteroid treatment. Mutilans deformity at the MCP joints was associated with subluxation in the neck and with corticosteroid treatment.

Involvement of the cervical spine is common in rheumatoid arthritis (RA). Its incidence (Table 1) is variously reported as between 40 and $88 \%$ (Sharp and Purser, 1961; Bland et al., 1963; Conlon et al., 1966). Its pathology is well reviewed by Ball and Sharp (1971). It is generally accepted that deformities of the cervical spine in RA are more severe following treatment with corticosteroids, but a critical analysis is needed to determine to what extent this is so.

The main problem is to distinguish between the effect of the disease and the effect of the corticosteroids. Does corticosteroid treatment enhance

Table 1 Incidence of cervical spine involvement in $R A$

\begin{tabular}{llll}
\hline Study & $\begin{array}{l}\text { No. of } \\
\text { patients }\end{array}$ & $\begin{array}{l}\text { Basis of } \\
\text { evidence }\end{array}$ & $\begin{array}{l}\text { Incidence } \\
(\%)\end{array}$ \\
\hline Bland et al. (1963) & 100 & $x$-ray & 86 \\
Conlon et al. (1966) & 333 & $x$-ray & 50 \\
Conlon et al. (1966) & 333 & Clinical & 88 \\
Sharp and Purser (1961) & 44 & Clinical & 40 \\
\hline
\end{tabular}

Accepted for publication February 2, 1978

* Present address: Ziekenhuis Ziekenzorg, Enschede, The Netherlands. the changes caused by the disease, or does it produce additional changes of a different nature? Or is it merely that those patients given corticosteroid treatment are automatically those with the worst and most destructive disease?

Also, an association has been noted between mutilans deformities in the hands and rheumatoid lesions in the neck, but this is a point on which specific information is lacking. Again, does corticosteroid treatment have a role in adding to, or in worsening these lesions?

We have attempted to answer these questions by radiological studies made during the course of a follow-up review of patients with RA of 15 years' duration, just over half of whom had been treated with corticosteroids. Our purpose here is (a) to identify radiologically the effect of the disease and the effect of corticosteroids on the cervical spine in a group of patients who had all suffered from RA for a similar period, (b) to relate these changes to the severity of the disease as a whole, and (c) to see what association exists between cervical spine lesions, corticosteroid treatment, and mutilans deformities in the hands and $x$-ray changes in hands and wrists. 
The patients

The 62 patients studied (19 men, 43 women) were among the 65 survivors of an original group of 100 patients with definite or classical RA initially seen by J.A.C. within the first year of their disease. When first seen the mean duration of RA was 3.7 months. Features of the onset of the disease, and an 11-year follow-up have already been published (Jacoby et al., 1973). At the time of this study the mean duration of the disease was 14.6 years (SD $1.75)$ and the mean age of the patients was $61 \cdot 1$ years (SD 12.8). In all, 65 of the original 100 were alive and were examined when the follow-up study was made in 1975, but our report is based on the 62 for whom satisfactory radiographs were available. Twenty-nine had never been treated with corticosteroids or ACTH, while 33 had been so treated for periods ranging from 1 to 17 years.

\section{Methods}

Lateral radiographs of the cervical spine were taken in full flexion and full extension, using a $5 \mathrm{ft}$ tubeto-plate distance and centered on the second vertebra. $X$-rays were read according to an agreed plan and without knowledge of the clinical details. For the assessment of rheumatoid damage to the cervical spine we used the 10 radiological criteria for diagnosis of RA of the cervical spine, as given by Bland (1974), which we have called the 'Bland criteria' (Table 2). Bone demineralisation was assessed only subjectively as present or absent. Measurements of atlanto-axial space were made on the flexion film between the mid-point of the posterior surface of the anterior arch of the atlas and the nearest point of the odontoid process. McGregor's line (1948) between palate and occiput was used to assess vertical atlanto-axial subluxation.

In the lower cervical spine, loss of alignment of $1 \mathrm{~mm}$ or more between the posterior profiles of two adjacent vertebral bodies on the flexion film was

Table 2 Radiological criteria for diagnosis of rheumatoid arthritis of the cervical spine (Bland, 1974)

\footnotetext{
Atlanto-axial subluxation of $2.5 \mathrm{~mm}$ or more

2 Multiple subluxation of C2-3, C3-4, C4-5, C5-6

3 Narrow disc spaces with little or no osteophytosis

(a) Pathognomonic of RA at C2-3 and C3-4

(b) Probable RA at C4-5 and C5-6

4 Erosions of vertebrae, especially vertebral plates

5 Odontoid small, pointed, and eroded with loss of cortex

6 Basilar impression ('platybasia')

7 Apophyseal joint erosion; blurred facets

8 Generalised osteoporosis in cervical spine

9 Wide space ( $5 \mathrm{~mm}$ or more) between posterior arch of atlas and the spinous process of the axis (in flexion)

10 Osteosclerosis, secondary, of atlanto-axial occipital complex
}

also measured. We preferred the posterior profile to the more commonly used anterior measurement as the anterior faces of the vertebrae in RA are ofterw uneven making it difficult to measure subluxation: accurately. The displacement (mm) at each disc level? was recorded and summated to yield the 'luxation total'.

The clinical diagnosis of mutilans deformity was based on the presence of bony destruction an ligamentous laxity, permitting longitudinal 'teles scoping' and volar subluxation at the metacarpophalangeal (MCP) joints. Radiological damage at the MCP joints and at the wrists was assessed separately, and abnormalities were graded as absent? mild, moderate, or severe (Table 3 ). If there waš doubt about the presence of a radiological sign, it was regarded as normal.

The severity of RA in its effect upon the patient's health and activity cannot be expressed precisely, aso can, for example, pulmonary function in patients with bronchial asthma. In assessing $\mathbf{R A}$ therefore we used indirect, clinical indicators of severity namely ESR, haemoglobin, and Rose titre, and the widely accepted ARA grading into possible, prob 3 able, definite and classical RA, which is based on laboratory and clinical criteria (Table 4). Functional. capacity was assessed by the 4 grades definedof by Steinbrocker et al. (1949): $1=$ fit for all activites, $2=$ moderate restriction; $3=$ marked restrict $4=$ confined to chair or bed. In addition, recorded the presence or absence of rheumatoid nodules. There were thus 6 indicators of severity.

\section{Results}

EFFECTS OF RA ON CERVICAL SPINE For each patient we compared the clinical indicato of severity with Bland's radiological criteria of damage. Table 5 sets out the statistical correlation between each of the 6 indicators and the Blan criteria. The latter are indicated as the total number

Table 3 Grading of radiological damage in $M C P$ joints and carpal bones

\begin{tabular}{ll}
\hline Absent & No abnormalities \\
Mild & Osteoporosis, 1 or 2 cysts \\
Moderate & Many cysts, some erosions \\
Severe & Destruction of joints and bone edges \\
\hline &
\end{tabular}

Table 4 Indicators of systemic severity of $R A$

\begin{tabular}{|c|c|c|}
\hline $\begin{array}{l}\text { Laboratory } \\
\text { Clinical } \\
\text { Combined }\end{array}$ & $\begin{array}{l}\text { ESR (mm in first hour) } \\
\text { Hb ( } / \text { /dl) } \\
\text { Rose titre (no. of tubes) } \\
\text { Functional capacity } \\
\text { Presence of nodules } \\
\text { ARA Grading }\end{array}$ & 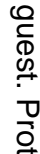 \\
\hline
\end{tabular}


Table 5 Correlation between clinical indicators of severity of $R A$, radiological evidence of damage in neck (Bland criteria), and 'luxation total'

\begin{tabular}{|c|c|c|c|c|}
\hline \multirow{2}{*}{$\begin{array}{l}\text { Indicator of } \\
\text { severity }\end{array}$} & \multirow{2}{*}{$\begin{array}{l}\text { Correlation with } \\
\text { number of Bland } \\
\text { criteria present }\end{array}$} & \multicolumn{2}{|c|}{ Correlation with individual Bland criteria 3-10* } & \multirow{2}{*}{$\begin{array}{l}\text { Luxation } \\
\text { total } \\
(\mathrm{mm})\end{array}$} \\
\hline & & $P<0.01$ & $P<0.05$ & \\
\hline ESR & NS & Criterion 3 & Criterion 5 & $\begin{array}{l}\mathbf{P}<0.05 \\
\mathbf{r}=+0.280\end{array}$ \\
\hline $\mathbf{H b}$ & $\begin{array}{l}P<0.05 \\
r=-0.316\end{array}$ & Criteria 3, 5 & None & NS \\
\hline Rose titre & $\begin{array}{l}\mathrm{P}<0.01 \\
\mathrm{r}=+0.352\end{array}$ & None & None & NS \\
\hline $\begin{array}{c}\text { Functional } \\
\text { capacity }\end{array}$ & $\begin{array}{l}P<0.001 \\
r=+0.462\end{array}$ & None & Criteria 3, 5, 6 & NS \\
\hline Nodules & $\begin{array}{l}P<0.05 \\
t=2.17\end{array}$ & None & None & NS \\
\hline $\begin{array}{l}\text { ARA grade } \\
\text { (see Table 6) }\end{array}$ & $P<0.01$ & Criteria 5, 7 & Criteria 3, 9 & $\mathbf{P}<0.05$ \\
\hline
\end{tabular}

* See Table 2.

Table 6 Correlation between ARA grading, radiological evidence of damage (Bland criteria), and luxation

\begin{tabular}{lccc}
\hline ARA grade & No. & Number of Bland criteria & Luxation total (mm) \\
\hline Possible & 6 & $2 \cdot 8$ (SD 1.2) & 3.0 (SD 2.8) \\
Probable & 0 & 5.9 (SD 2.3) & 6.3 (SD 4.5) \\
Definite & 27 & $7 \cdot 3$ (SD 1.8) & $8 \cdot 2$ (SD 5.2)
\end{tabular}

Significance of difference

Possible and definite; $\mathrm{P}<0.01$

Possible and classical; $\mathbf{P}<0.001$

Possible and classical: $\mathrm{P}<0.05$

Initially all patients were in the grades 'definite' and 'classical', but during the 15-year follow-up, 6 had improved and were placed in the 'possible' grade.

of criteria found for each patient, and also as individual criteria 3-10 (omitting 1 and 2, which concern luxation). Table 6 shows in more detail the ARA gradings related to the number of Bland criteria present.

Each of the 6 indicators of disease severity correlated in some degree with radiological criteria of damage. We interpreted this as meaning that damage to cervical spine other than luxation is closely related to the severity of the disease as a whole. The individual criteria of radiological damage which showed the closest association were 3 and 5 , ie, narrowing of disc spaces without osteophytosis, and erosion of odontoid.

A similar comparison was made between the clinical indicators of disease severity and the 'luxation total' (Tables 5 and 6). Here correlation was less close, and was seen only with 2 of the 6 indicators of severity ie, the ESR and the ARA grading.

The observation that disease severity was more closely associated with radiological signs of damage in the cervical spine than with luxation was, we thought, consistent with the concept that luxation might be attributable in part to another factor, ie, corticosteroid treatment.
EFFECTS OF CORTICOSTEROID TREATMENT

We studied the 'luxation total' in relation to corticosteroid treatment and its duration. Fig. 1 shows that the 29 patients who had had no corticosteroids, had luxation totals ranging from $0-12 \mathrm{~mm}$, while the 33 who had had corticosteroids showed a wider range, up to a maximum of $22 \mathrm{~mm}$. Of the 62 patients there were 9 with luxation totals over 10 $\mathrm{mm} ; 8$ of these 9 had had corticosteroids for 7 years or more.

The mean 'luxation total' in the group without corticosteroids was $5 \mathrm{~mm}$ (SD 3.36) compared with $8.72 \mathrm{~mm}$ (SD 5.48) in the group given corticosteroids-a significant difference $(P<0 \cdot 01)$. Fig. 1 also shows a slight degree of correlation between the duration of corticosteroid treatment and the 'luxation total'.

We concluded that prolonged corticosteroid treatment has some effect in increasing luxation in the cervical spine, an effect which is separate from that of the rheumatoid arthritis. +

MUTILANS DEFORMITIES

Ten of the 62 patients had mutilans deformities of the MCP joints. The presence or absence of such deformities was compared with the state of the 


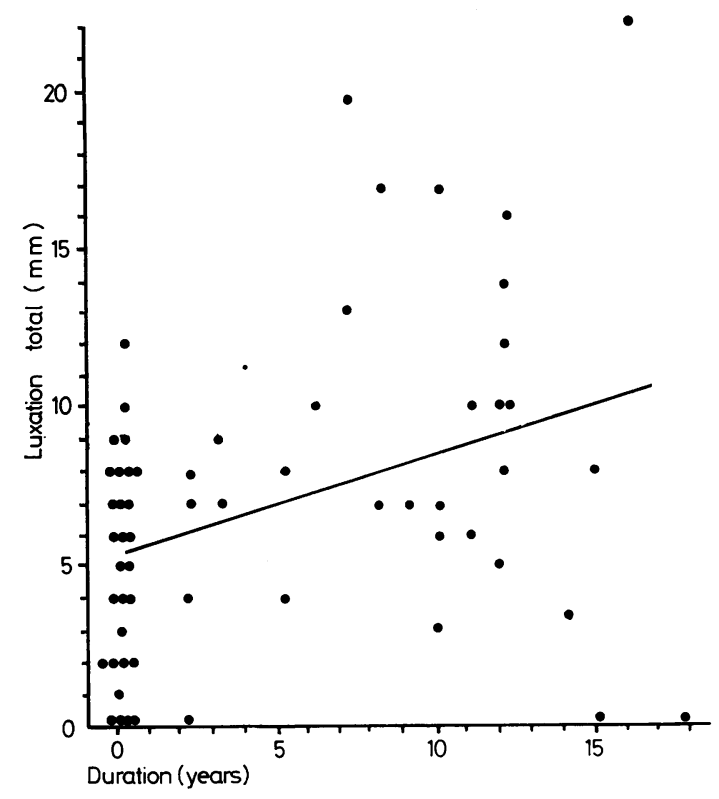

Fig. 1 The 'luxation total' in the cervical spine shown in relation to the duration of corticosteroid treatment in 62 patients. Thirty-three had been treated for periods up to 17 years, and 29 had never had corticosteroids. The 'luxation total' is significantly greater $(P<0.01, r=0.3489)$ in those given corticosteroids and tends to increase in relation to the duration of treatment.

cervical spine, viz, the numbers of Bland criteria present, and the luxation total, and also with the duration of corticosteroid treatment (Table 7).
Mutilans deformities were not associated with a higher number of Bland criteria, but were associated 0 with a significantly greater luxation total, with corticosteroid treatment and with the duration of $\overrightarrow{\vec{F}}$ treatment. Moreover, in all 10 patients with mutilans deformities, corticosteroids had been given for over 3 years.

\section{RADIOLOGICAL DAMAGE IN MCP JOINTS AND CARPAL BONES}

\section{Comparison with cervical spine}

The severity of radiological damage in the MCP joints was compared with radiological signs of damage and of luxation in the neck. A significant association was found with the number of Bland. criteria, with the luxation total and with corti-o costeroid treatment (Table 8). A similar comparison of radiological damage in the carpal bones showed the same association with changes in the neck and with corticosteroid treatment (Table 9).

Comparison with disease severity

Abnormalities in 5 of the 6 indicators of disease severity, ie, all but the ESR, were found to be significantly associated with the severity of damage in the MCP joints. A less close association, applying. to only 3 of the 6 indicators, was found when conparing them with the severity of damage to the carpal bones (Table 10).

Close similarities were thus found, as might be expected, between radiological signs of damage in $\mathbb{\perp}$ the hand and wrist, and the neck, with a relationship $\overrightarrow{\vec{P}}$

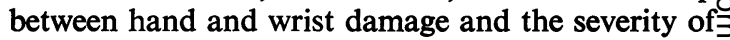

Table 7 Presence of mutilans changes in MCP joints compared with changes in cervical spine and duration of corticosteroid treatment

\begin{tabular}{|c|c|c|c|c|c|}
\hline $\begin{array}{l}\text { Mutilans in } \\
\text { MCPs }\end{array}$ & No. & $\begin{array}{l}\text { Number of } \\
\text { Bland criteria }\end{array}$ & $\begin{array}{l}\text { Luxation total } \\
(\mathrm{mm})\end{array}$ & $\begin{array}{l}\text { Corticosteroid } \\
\text { treatment }\end{array}$ & $\begin{array}{l}\text { Duration of } \\
\text { corticosteroid treatment (years) }\end{array}$ \\
\hline $\begin{array}{l}\text { Present } \\
\text { Absent }\end{array}$ & $\begin{array}{l}10 \\
52\end{array}$ & $\begin{array}{l}7 \cdot 6\left(\mathrm{SD}_{1} \cdot 1\right) \\
6 \cdot 0(\mathrm{SD} 2 \cdot 4)\end{array}$ & $\begin{array}{r}12 \cdot 1(\mathrm{SD} \mathrm{6} \cdot 2) \\
5 \cdot 7(\mathrm{SD} \mathrm{3} \cdot 7)\end{array}$ & $\begin{array}{l}10 \\
23\end{array}$ & $\begin{array}{l}9 \cdot 1(\text { SD 3.2) } \\
3 \cdot 9(\mathrm{SD} 5 \cdot 6)\end{array}$ \\
\hline Significance & & NS & $\begin{array}{l}P<0.001 \\
t=3.73\end{array}$ & $\begin{array}{l}P=0.0002 \\
\text { (Fisher's exact test) }\end{array}$ & $\begin{array}{l}P<0.01 \\
t=2.84\end{array}$ \\
\hline
\end{tabular}

Table 8 Severity of radiological damage in MCP joints compared with changes in cervical spine and corticosteroid treatment

\begin{tabular}{|c|c|c|c|c|c|}
\hline \multirow[t]{2}{*}{$\begin{array}{l}\text { Severity of } \\
\text { damage in } M C P\end{array}$} & \multirow[t]{2}{*}{ No. } & \multirow[t]{2}{*}{$\begin{array}{l}\text { Number of } \\
\text { Bland criteria }\end{array}$} & \multirow[t]{2}{*}{$\begin{array}{l}\text { Luxation total } \\
(\mathrm{mm})\end{array}$} & \multicolumn{2}{|c|}{$\begin{array}{l}\text { Corticosteroid } \\
\text { treatment }\end{array}$} \\
\hline & & & & No & Yes \\
\hline $\begin{array}{l}\text { Absent or mild } \\
\text { Moderate } \\
\text { Severe }\end{array}$ & $\begin{array}{l}24 \\
19 \\
19\end{array}$ & $\begin{array}{l}4.6(\text { SD } 2 \cdot 2)^{*} \\
7.4(\text { SD } 1 \cdot 5) \\
7.5(\text { SD } 1 \cdot 7)\end{array}$ & $\begin{array}{l}4 \cdot 1(\text { SD 3.0)* } \\
8 \cdot 1(\text { SD 3.9) } \\
9 \cdot 4(\text { SD 6.1) }\end{array}$ & $\begin{array}{r}16 \\
7 \\
6\end{array}$ & $\begin{array}{r}8 \\
12 \\
13\end{array}$ \\
\hline Significance & & \multicolumn{2}{|c|}{$\begin{array}{l}* \mathbf{P}<0.001 \text { compared with either moderate } \\
\text { or severe classes }\end{array}$} & \multicolumn{2}{|c|}{$\begin{array}{l}0.01<P<0.05 \\
x^{2}=6.34\end{array}$} \\
\hline
\end{tabular}


Table 9 Severity of radiological damage in carpal bones compared with changes in cervical spine and corticosteroid treatment

\begin{tabular}{|c|c|c|c|c|c|}
\hline $\begin{array}{l}\text { Severity of } \\
\text { damage in carpal bones }\end{array}$ & No. & $\begin{array}{l}\text { Number of } \\
\text { Bland criteria }\end{array}$ & $\begin{array}{l}\text { Luxation total } \\
(\mathrm{mm})\end{array}$ & $\begin{array}{l}\text { Corticosteroid } \\
\text { No }\end{array}$ & Yes \\
\hline $\begin{array}{l}\text { Absent or mild } \\
\text { Moderate } \\
\text { Severe }\end{array}$ & $\begin{array}{l}13 \\
12 \\
37\end{array}$ & $\begin{array}{l}4 \cdot 2(\text { SD 2.5) } \\
5 \cdot 3(\text { SD 2.4) } \\
7 \cdot 3(\text { SD 1.6) }\end{array}$ & $\begin{array}{l}3.8(\text { SD } 2 \cdot 7) \\
4 \cdot 2(\text { SD } 3 \cdot 8) \\
8.9(\text { SD } 4 \cdot 9)\end{array}$ & $\begin{array}{r}9 \\
8 \\
12\end{array}$ & $\begin{array}{r}4 \\
4 \\
25\end{array}$ \\
\hline Significance & \multicolumn{3}{|c|}{$\begin{array}{l}\mathbf{P}<0.01 \text { absent or mild/severe } \\
\mathbf{P}<0.01 \text { moderate/severe }\end{array}$} & \multicolumn{2}{|l|}{$\begin{array}{l}P<0.05 \\
\chi^{2}=7.61\end{array}$} \\
\hline
\end{tabular}

Table 10 Correlation between clinical indicators of severity of $R A$ and radiological damage to $M C P$ joints and carpal bones

\begin{tabular}{llc}
\hline Indicator of severity & \multicolumn{2}{c}{$\begin{array}{c}\text { Correlation with severity of } \\
\text { radiological damage }\end{array}$} \\
\cline { 2 - 3 } & MCP joint & Carpal bones \\
\hline ESR & $\mathrm{NS}$ & $\mathrm{NS}$ \\
Hb & $0.01<\mathbf{P}<0.05$ & $\mathrm{NS}$ \\
Rose titre & $0.01<\mathbf{P}<0.02$ & $\mathbf{P}<0.01$ \\
Functional capacity & $\mathbf{P}<0.01$ & $0.01<\mathbf{P}<0.05$ \\
Nodules & $\mathbf{P}<0.01$ & $\mathrm{NS}$ \\
ARA grade & $\mathrm{P}<0.001$ & $\mathrm{P}<0.001$ \\
\hline
\end{tabular}

RA as a whole. However, mutilans deformities in the MCP joints differed somewhat in being related more to luxation in the neck and to corticosteroid treatment, than to structural damage in the neck.

\section{ATLANTO-AXIAL SUBLUXATION}

Twenty-six of our 62 patients $(42 \%)$ had atlantoaxial subluxation (AAS) ie, an atlanto-axial space, as defined above, of $3 \mathrm{~mm}$ or more. We found associations between AAS and corticosteroid treatment, and the degree of severity of damage in the MCP joint and wrists, and the presence of nodules. Thus, the mean atlanto-axial distance was significantly greater in patients who had had over 5 years of corticosteroid treatment than in those who had never had corticosteroids $(\mathrm{P}<0.002, \mathrm{t}=2.55)$. More severe radiological changes in the MCP joints were associated with the presence of AAS and a greater mean atlanto-axial distance (Table 11). The same relationship was found for carpal damage, the presence of AAS, and the mean atlanto-axial distance (Table 12). AAS was also significantly more frequent in patients having rheumatoid nodules (Table 13). In short, AAS was virtually only found in those patients with considerable damage to MCP joints and wrists.

\section{VERTICAL ATLANTO-AXIAL SUBLUXATION}

This was present in 20 of our 62 patients $(32 \%)$ by McGregor's criterion of having the tip of the odontoid more than $4.5 \mathrm{~mm}$ above McGregor's line (McGregor, 1948). Of these 20, 8 had been treated with corticosteroids.

Table 11 Severity of radiological damage in MCP joints compared with atlanto-axial subluxation (AAS)

\begin{tabular}{|c|c|c|c|c|}
\hline$M C P$ damage & No. & $A A S$ present & Mean atlanto-axial distance $(\mathrm{mm})$ & Significance \\
\hline None or mild & 24 & 2 & $1.04($ SD 1.30) & $t^{\text {mild } / \text { severe }=3.82, P<0.001}$ \\
\hline Moderate & 19 & 11 & $2.66($ SD 1.89) & $\mathrm{t}^{\mathrm{mild} / \text { moderate }}=3 \cdot 32, \mathrm{P}<0.001$ \\
\hline Severe & 19 & 13 & 3.89 (SD 3.36) & NS \\
\hline
\end{tabular}

Table 12 Severity of the radiological damage in carpal bones compared with atlanto-axial subluxation (AAS)

\begin{tabular}{lllll}
\hline Carpal damage & No. & AAS present & Mean atlanto-axial distance $($ mm $)$ & Significance \\
\hline None or mild & 13 & 0 & 0.85 (SD 0.99) & t \\
Moderate & 12 & 1 & 0.67 (SD 1.07) & severe $=3.55$, P $<0.001$ \\
Severe & 37 & 25 & 3.54 (SD 2.65) & moter $/$ severe $=3.63$, P $<0.001$ \\
\hline
\end{tabular}

Table 13 Atlanto-axial subluxation and the presence of rheumatoid nodules

\begin{tabular}{lllll}
\hline Nodules present & No. & AAS present & Atlanto-axial distance $($ mm) & Significance \\
\hline Yes & 15 & 13 & $3 \cdot 80$ (SD 1.86) & P $<0.05$ \\
No & 47 & 13 & $1 \cdot 97$ (SD 2.59) & $t=2 \cdot 53$ \\
\hline
\end{tabular}


Table 14 Functional capacity related to treatment with corticosteroids

\begin{tabular}{|c|c|c|c|c|}
\hline \multirow[t]{2}{*}{ Steroids given } & \multicolumn{4}{|c|}{ Functional capacity } \\
\hline & 1 & 2 & 3 & 4 \\
\hline $\begin{array}{l}\text { No } \\
\text { Yes }\end{array}$ & $\begin{array}{l}6 \\
2\end{array}$ & $\begin{array}{r}14 \\
9\end{array}$ & $\begin{array}{r}7 \\
18\end{array}$ & $\begin{array}{l}2 \\
4\end{array}$ \\
\hline Significance & \multicolumn{4}{|c|}{$\begin{array}{l}\text { Combining classes } 1 \text { and } 2 \text {, and } 3 \text { and } 4 \\
\chi^{2}=6.48 \text { and } 0.01<P<0.05 \\
\text { (ie, functional capacity is worse in } \\
\text { patients given corticosteroids. }\end{array}$} \\
\hline
\end{tabular}

CORTICOSTEROID TREATMENT AND SEVERITY OF THE DISEASE

Patients who had been treated with corticosteroids and those who had not, were compared to see whether corticosteroid treatment necessarily implied more severe RA. For the most part, indicators of severity of disease were not related to corticosteroid treatment. Thus ESR, haemoglobin, Rose titre, and the ARA grading did not significantly differ in the two classes. However, there was some evidence that functional capacity was worse in patients given corticosteroids (Table 14).

\section{Discussion}

In this study the duration of RA is not a significant factor in that all patients had had the disease for a similar period. Nor was selection of patients of importance, for entry into the original series of 100 patients 15 years previously was purely on the grounds of the patients then having newly developed RA, and attaining the ARA grades of 'definite' or 'classical' RA within 1 year of onset.

Fortuitously the numbers of patients treated and not treated with corticosteroids were roughly equal (33 and 29, respectively), making them groups suitable for comparison. In general, patients having corticosteroids had no evidence of more severe rheumatoid disease, with the exception of functional capacity, for which they rated rather worse than those not on corticosteroids. Matters may have been different at an earlier stage, before the introduction of corticosteroids, but we found it impracticable to take previous progress into account, and based our assessment purely upon the situation found at the 15-year survey. Similarly, the question of corticosteroid dosage was too complex to assess, for patients had been on variable regimes. We found it simplest merely to group together those who had had corticosteroids (including the few who had had $\mathrm{ACTH}$ ), irrespective of dosage, and to confine our attention to duration of treatment.

In general, we found that the presence of Bland's radiological criteria of rheumatoid damage to the cervical spine correlated well with the indicators $\stackrel{\mathbb{D}}{\overline{\mathrm{g}}}$ severity of rheumatoid disease as a whole. The individual features of greatest significance in the sense were narrowing of disc spaces, and erosion anta pointing of the odontoid process (criteria 3 and 5 . Those of least significance were erosions of vertebial plates, generalised osteoporosis and osteosclerosis ơf atlanto-axial complex (criteria 4, 8, and 10).

Bland's criteria include subluxation between atlas and axis, and subluxation at lower levês (criteria 1 and 2), but we preferred to attempt $\vec{c}$ quantitative assessment of the process of subluxation throughout the neck in the form of the luxation total'. This was measured from a lateral radiogra: taken with the neck in flexion. It is difficult know how much this total figure may be influencest by the degree of flexion achieved, and in practicio, such positioning for radiography cannot be precisisy standardised. In the event, each patient was merefy asked to bend his or her head forwards as far as possible, with chin on chest. The question arises of whether patients on corticosteroids can achieve greater degree of flexion and thus subluxation, thôn those not on corticosteroids. However, from inspection of the $x$-ray films we have no reason $\Phi_{0}$ believe that there was any difference between theste groups in their positioning for radiography.

Our analysis indicates that, while subluxation in the cervical spine occurs as a result of rheumatopd arthritis, the situation is worsened by corticosterowd treatment. There is some evidence that worseni subluxation is related to duration of corticosteroged treatment, both in the cervical spine as a whole apd at the atlanto-axial articulation. Similarly mutila⿳亠㐅⿵冂⿰ deformity at the MCP joints, we found, was related to corticosteroid treatment rather than to the severity of the disease as a whole.

We suggest that subluxation is favoured rheumatoid subjects in the absence of corticosteroif therapy, by reduction in bone mass and a weakenio effect on ligaments and connective tissue. Thèse changes can also occur in non-rheumatoid subjects on corticosteroid therapy and are naturally enhancegd in rheumatoid patients given corticosteroids. It would be of interest to know whether cervical steluxation may also develop in non-rheumatơ patients on long-term corticosteroid treatment for other conditions.

Sharp et al. (1958) were among the first to dra attention to subluxation in the cervical spine due 40 rheumatoid arthritis. They also noted the association of rheumatoid damage in the cervical spine wh damage to the hands and feet, pointing out the increased frequency of radiological changes in hands and feet in patients with more severe neck lesions.

We confirmed this, as regards the hands and 
wrists, finding an association between the severity of damage in the MCP joints and carpal bones and the severity of damage in the cervical spine.

The forward subluxation of atlas on axis has been widely studied. Our incidence of $42 \%$ is rather higher than in surveys, ie, $9 \%$ quoted by Smith et al. (1972), $19 \%$ by Sharp and Purser (1961), $25 \%$ by Mathews (1969), 36\% by Stevens et al. (1971), 37\% by. Meikle and Wilkinson (1971), and $37 \%$ by Serre et al. (1963). However, Martel (1961) quoted an even higher figure, $71 \%$, based on a series of 34 severely affected rheumatoid patients. Some association between AAS and duration of disease, and corticosteroid therapy was found by Meikle and Wilkinson (1971), although details were not given of the degree of subluxation nor of the duration of corticosteroid therapy, and the series appeared to have been biased by the selection of patients with neck symptoms. Mathews (1969) also found a significant association between AAS and corticosteroid treatment and Smith et al. (1972) reported more rapid deterioration in neck lesions in corticosteroid treated patients. Serre et al. (1963) noted a higher proportion of AAS in those patients given prolonged high dose corticosteroids (62\%) than in other rheumatoid patients $(38 \%)$. Lourie and Stewart (1961) commented on the tendency for prolonged administration of corticosteroids in RA to produce 'disruptive changes' in the cervical spine.

As for other associations with AAS, Stevens et al. (1971) noted a relationship with 'hand deformities', and with nodules, as did Conlon et al. (1966) and as we did. Vertical atlanto-axial subluxation is recorded less commonly than AAS, being noted in only $1 \%$ by Smith et al. (1972) and $4 \%$ by Henderson (1975). Compared with this, our figure of $32 \%$ is surprisingly high. The role of corticosteroid treatment in inducing this form of subluxation appears to be of less importance than is the case with forward subluxation.

We wish to thank Mrs Elizabeth Collins for the statistical analyses and Dr L. Jackson for help in the analysis of radiographs.

J.J.R. is in receipt of a grant from the Nederlandse Vereniging tot rheumatickbestrijding.

\section{References}

Ball, J. and Sharp, J. (1971). Rheumatoid arthritis of the cervical spine. In Modern trends in Rheumatology II, ed. by A. G. S. Hill, pp. 117-138. Butterworth: London.

Bland, J. H. (1974). Rheumatoid arthritis of cervical spine. Journal of Rheumatology, 1, 319-342.

Bland, J. H., Davis, P. H., and London, M. G. (1963). Rheumatoid arthritis of the cervical spine. Archives of Internal Medicine, 112, 892-898.

Conlon, P. W. Isdale, I. C., and Rose, B. S. (1966). Rheumatoid arthritis of the cervical spine. Annals of the Rheumatic Diseases, 25, 120-126.

Henderson, D. F. R. (1975). Vertical atlanto-axial subluxation in rheumatoid arthritis. Rheumatology and Rehabilitation, 14, 31-38.

Jacoby, R. K., Jayson, M. I. V., and Cosh, J. A. (1973). Onset, early stages and prognosis of rheumatoid arthritis: A clinical study of 100 patients with 11-year follow-up. British Medical Journal, 2, 96-100.

Lourie, H., and Stewart, W. A. (1961). Prolonged administration of steroids producing a disruptive change in cervical spine. New England Journal of Medicine, 265, 677-681.

McGregor, M. (1948). The significance of certain measurements of the skull in the diagnosis of basilar impression. British Journal of Radiology, 21, 171-181.

Martel, W. (1961). The occipito-atlanto-axial joints in rheumatoid arthritis and ankylosing spondylitis. American Journal of Roentgenology, 86, 223-240.

Mathews, J. A. (1969). Atlanto-axial subluxation in rheumatoid arthritis. Annals of the Rheumatic Diseases, 28, 260-266.

Meikle, J. A. K., and Wilkinson, M. (1971). Rheumatoid involvement of the cervical spine. Annals of the Rheumatic Diseases, 30, 154-161.

Serre, H., Simon, L., Janicot, J.-Y., and Levy, F. (1963). Les affections rhumatismales de la charniere cervicooccipitale. Revue de Rhumatisme, 30, 518-544.

Sharp, J., and Purser, D. W. (1961). Spontaneous atlantoaxial dislocation in ankylosing spondylitis and rheumatoid arthritis. Annals of the Rheumatic Diseases, 20, 47-77.

Sharp, J., Purser, D. W., and Lawrence, J. S. (1958). Rheumatoid arthritis of the cervical spine in the adult. Annals of the Rheumatic Diseases, 17, 303-313.

Smith, P., Benn, R. T., and Sharp, J. (1972). Natural history of rheumatoid cervical luxations. Annals of the Rheumatic Diseases, 31, 431-439.

Steinbrocker, O., Traeger, C. N., and Batterman, R. C. (1949). Therapeutic criteria in rheumatoid arthritis. Journal of the American Medical Association, 140, 659-662.

Stevens, J. C., Cartilidge, N. E. F., Saunders, M., Appleby, A., Hall, M., and Shaw, D. A. (1971). Atlanto-axia subluxation and cervical myelopathy in rheumatoid arthritis. Quarterly Journal of Medicine, 40, 391-408. 